\title{
Experiment of New Additives Effect on Gas Hydrate Formation
}

\author{
Yuan Dai', Xiaoxia Zhong2, Xin Jiang'2, Shuli Wang1 ${ }^{*}$ \\ ${ }^{1}$ China Jiangsu Key Laboratory of Oil \& Gas Storage and Transportation Technology, School of Petroleum \\ Engineering, Changzhou University, Changzhou, China \\ ${ }^{2}$ Offshore Oil Engineering Corp, Tianjin, China \\ Email: *wsl@cczu.edu.cn
}

Received 25 April 2014; revised 25 May 2014; accepted 31 May 2014

Copyright (C) 2014 by authors and Scientific Research Publishing Inc.

This work is licensed under the Creative Commons Attribution International License (CC BY).

http://creativecommons.org/licenses/by/4.0/

c) (i) Open Access

\begin{abstract}
Natural gas hydrate has tremendous gas storage capacity; natural gas hydrate can be used to store and transport energy. The current problem faced is how to improve the hydrate formation rate and storage capacity, and form continuously. Compared to the pure water and SDBS solution, the ionic solution [HMIPS] OTs made by the team was the excellent additive and ensured the best reaction concentration range. Specific effects of different additives on hydrate formation were summarized; hydrate formation mechanism of additives was expounded. Considering the investment cost, operation cost, simple and stable operation of different surfactants, it is thought that the study of different additives mechanisms and developing the new efficient additive have the important value.
\end{abstract}

\section{Keywords}

Gas Hydrate, Formation Promote, Additive, Principle, Phase Equilibrium

\section{Introduction}

Gas hydrate is ice-like compounds formed from water and various guest gas molecules. It has huge gas storage capacity that $1 \mathrm{~m}^{3}$ of hydrate can store $160-180 \mathrm{~m}^{3}$ natural gas. Due to the question of lack of energy, environment degradation became more and more seriously. Nature gas hydrates formation technology, which caused the attention of the scholars at home and abroad, can be used such as hydrate gas separation, natural gas transportation and marine $\mathrm{CO}_{2}$ waste treatment. Compared to the LNG and CNG, natural gas hydrate storage and transportation technology (NHG) has obvious advantages that much lower investment cost, operation cost, and are

"Corresponding author. 
safer, simple and stable operation. Gudmundsson et al. [1] confirmed that in atmospheric pressure, methane gas can be long-term stored in hydrate above $258.15 \mathrm{~K}$, however, LNG storage requires in $111.15 \mathrm{~K}$ condition, and the price of natural gas hydrate device is only $25 \%$ of LNG. The hydrate method to store and transport natural gas has the broad application prospect [2].

The current problem faced is how to improve the hydrate formation rate and storage capacity, and form continuously. A lot of experiments were done in order to solve this problem, it is expected that gas can be stored and transported in form of hydrate which is more economical than traditional method [3]. This paper analyzes the experiment of different additives effects on gas hydrate formation, and summarizes the effect of additives in terms of formation rate and gas storage capacity, and achievements.

\section{Types of Surfactant and Action Principle}

There are many kinds of surfactant, and can be roughly divided into anionic surfactant, cationic surfactant, amphoteric surfactant and non-ionic surfactant. Currently surfactants used for natural gas hydrate formation promoting are mostly anionic and non-ionic surfactants. It is noticed that chemical additives such as THF, SDS, SDBS and APG are researched most widely currently. What's more, lots of scholars home paid attention to the compound additives [4] [5] and series of tween additives [6]-[8]. The effect of each additive is different. What's more, every additive has defects such as THF will reduce the air tightness storage; APG has promoting effect only under the high concentration.

Hydrate formation is coupling of heat and mass transfer process. The mainly reinforcement method, which laboratory studies most, was mechanical method and chemical method. The surfactant that added to natural gas hydrate system can reduce gas-water interfacial tension, which can decrease the inter phase diffusion resistance and solubility of gas molecules in solution. Due to this, the contacting area of gas-liquid is increased, that makes it more likely to generate hydrate crystal nucleus, and speed up hydrate nucleation, shorten induction time and improve efficiency of hydrate formation.

The surfactant that reduces the tension of gas-water interfacial is added to system of natural gas hydrate system, so that inter phase diffusion resistance is decreased, and solubility of gas molecules in solution is increased. Because of this, gas-liquid contacting area is increased, that makes it more likely to generate hydrate crystal nucleus, and speed up hydrate nucleation, shorten induction time and improve efficiency of hydrate formation.

Luo $\mathrm{Hu}$ [9] using suspension bubble method determined growth rate of methane hydrate film in SDS solution of different concentration at temperature $273.35 \mathrm{k}, 275.35 \mathrm{k}, 277.35 \mathrm{k}, 279.35 \mathrm{k}$ and pressure 3.95 - 11.30 MPa. It is shown that temperature in high pressure chamber has more influence to hydrate than low pressure, and press has more influence to hydrate film growth rate in lower temperature. Interfacial tension decrease and "Interface compatibilization" were viewed as the main reason to hydrate promoting effect of SDS at low concentration (50 $\mathrm{mg} / \mathrm{L}$ or $100 \mathrm{mg} / \mathrm{L})$.

The different kinds of new additives used in experiment are given in Table 1. CTAB belongs to cationic surfactant. P123 and PEG was non-ionic surfactant. [HMIPS]OTs and [HMIPS]Ss were made by the team.

\section{Experiment Apparatus}

Experiment set-up comprises the visualization reaction kettle, magnetic stirring system, refrigeration system of constant temperature water bath and so on. Through the apparatus, the variation of kettle temperature could be monitored, the form and decompose of gas hydrate could be observed directly. Figure 1 illustrates a simplified schematic of the experiment test section where natural gas hydrates formation.

The design pressure of reaction still (15) was $30 \mathrm{Mpa}$ and the temperature was between $-10^{\circ} \mathrm{C}$ and $15^{\circ} \mathrm{C}$. Its volume was 0.5 litre and the magnetic stirring device (11) was actuated by permanent magnetic stirrer at the same time.

The reaction temperature was determined through putting the reaction kettle into salt bath sink of heat transfer (10). The temperature sensor (9) was made by Pt100 platinum resistance. Its range was $-50^{\circ} \mathrm{C}$ to $100^{\circ} \mathrm{C}$ and error band was $0.1^{\circ} \mathrm{C}$.

High pressure gas distribution system adopts advanced gas drive way, through the air compressor gas drive pressure pump after continuous operation make the rapid reaction gas pressurization import reaction kettle. Pneumatic pump (3) to pressure value through the valve can be closed at any time.

Reaction kettle temperature and pressure inside and outside display data are unified into current and voltage 
Table 1. The additives used in experiment.

\begin{tabular}{ccc}
\hline & Molecular formula & Manufacturer \\
SDBS & $\mathrm{C}_{18} \mathrm{H}_{29} \mathrm{NaO}_{3} \mathrm{~S}$ & \\
CTAB & $\mathrm{C}_{16} \mathrm{H}_{33}\left(\mathrm{CH}_{3} \mathrm{~N}_{3} \mathrm{Br}^{-}\right.$ & \\
P123 & $\left(\mathrm{C}_{2} \mathrm{H}_{4} \mathrm{O}\right) \mathrm{a}\left(\mathrm{C}_{3} \mathrm{H}_{6} \mathrm{O}\right) \mathrm{b}\left(\mathrm{C}_{2} \mathrm{H}_{4} \mathrm{O}\right) \mathrm{c}$ & \\
PEG & $\mathrm{HO}\left(\mathrm{CH}_{2} \mathrm{CH}_{2} \mathrm{O}\right) \mathrm{nH}$ & Made by USA \\
[HMIPS]OTs & {$\left[\mathrm{C}_{6} \mathrm{H}_{12} \mathrm{~N}^{+} \mathrm{HC}_{3} \mathrm{H}_{6} \mathrm{SO}_{3} \mathrm{H}\right] \mathrm{CH}_{3} \mathrm{C}_{6} \mathrm{H}_{4} \mathrm{SO}^{3-}$} & Synthesis by the team \\
[HMIPS]Ss & {$\left[\mathrm{C}_{6} \mathrm{H}_{12} \mathrm{~N}^{+} \mathrm{HC}_{3} \mathrm{H}_{6} \mathrm{SO}^{3-}\right] \mathrm{SO}_{4}^{2-}$} & Synthesis by the team \\
\hline
\end{tabular}

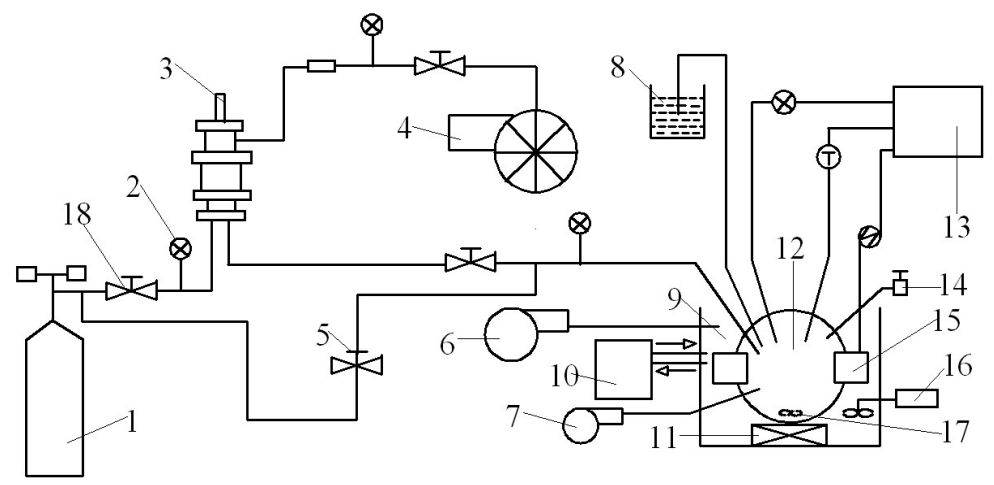

Figure 1. Experiment equipment for gas hydrate formation. 1-gas bomb; 2-piezometer; 3-gas booster pump; 4-air compressor; 5-needle valve; 6-water suction pump; 7-vacuum pump; 8-reaction solution; 9-thermostatic water bath; 10 - circulating slot; 11 -magnetic stirring device; 12 high pressure kettle; 13-computer; 14-air outlet; 15-glass lens; 16stirring system; 17-magnetic stirrer; 18 -globe valve.

data deliver to the computer (13) unified collect and analyze the transient pattern.

\section{Experiments of Additive Effect on Hydrate Formation}

\subsection{The Hydrate Formation Process and Characteristics in Mixing System}

Under the condition of not open the stirring, admission to $4.5 \mathrm{MPa}$ at temperature $5^{\circ} \mathrm{C}$, because of the reaction driving force at the three phase of gas-liquid-metal kettle wall was the largest, hydrate formed here firstly and then form a layer of hydrate film extend to liquid surface center. Because the effect of cold shower, the temperature of the wall was lowest that was mean the largest degree of subcooling; at the same time, the gas concentration was the largest in the solution that was mean the largest degree of supersaturation. So the hydrate will be formed firstly at the three-phase interface [5]. Because the hydrate film prevent the contact between the gas and liquid, the speed of formation in static system was very slow. Then due to the structure of hydrate film was needle loose, the effect of siphoning at the pore made gas and liquid had a contact, making it gradually thickening and form tentaculiform hydrate unceasingly extend to the liquid phase. After that, hydrate mainly formed at the kettle wall of three phases of hydrate phase-liquid-metal and with the drawdown and down and to extend to the reaction kettle.

Under the condition of open the stirring in the kettle and maintain the stirring speed at 500 - $600 \mathrm{rpm}$. Figure 2 shows the video screenshots of the process of hydrate formation recorded by video system. According to the reaction time ordered from left to right in turn. Through the picture we analyzed the process of hydrate formation under the condition of stirring system.

The initial temperature and pressure was constant, after admission obviously shorten the induction period than static environment, pressure dropt rapidly about $1 \mathrm{Mpa}$. After induction period, firstly in the liquid phase appeared some bubbles which diameter were $1 \mathrm{~cm}$. Surface rapidly formed hydrate shell then become thicker. Due to the buoyancy and stirring effect, rise up as spiral and then gather together automatically. The bubbles got smaller until it disappeared after about 1 min. Instead of liquid phase internal generated large amounts of grain 

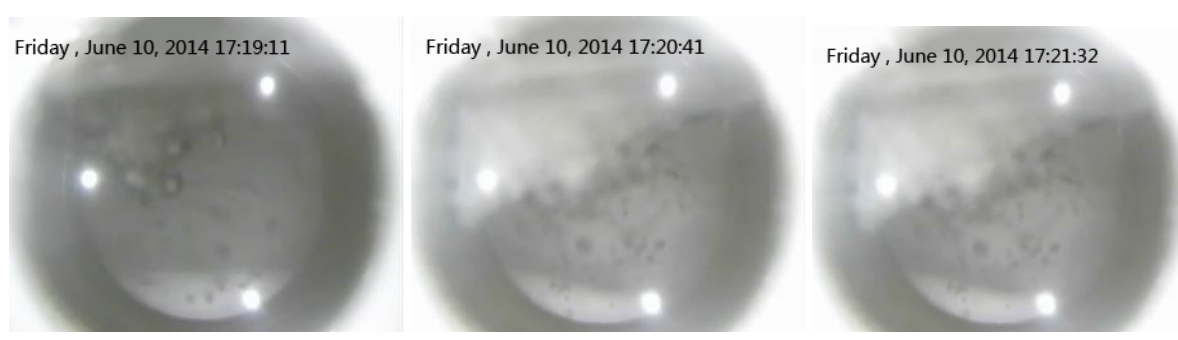

Figure 2. The hydrate formation process in mixing system.

which diameter were $1 \mathrm{~mm}$, a small temperature increase and then decrease to constant. Due to the effect of buoyancy and centrifugal force, grain tilted rotary float from the center of kettle bottom on liquid surface and after contacted with the hydrate block it adhesion to the mass gathered automatically more and more big and filling the department of space above liquid surface and filling the all kettle with the liquid level drawdown in 5 min. The pressure dropt about $0.4 \mathrm{Mpa}$ in the process of grain formation that was smaller than induction period that was mean dissolved gas to supersaturation was the key to form the hydrate. Finally, because the magnetic stirring grain was wrapped into clumps then stirring didn't work and subsequent reaction was completed in static environment.

\subsection{The Phase Equilibrium Curve Analysis}

Figures 3-8 show that $\mathrm{CO}_{2}$ hydrate phase equilibrium curve under different concentration of SDBS, CTAB, PEG, P123, [HMIPS]Ss, [HMIPS]OTs. As a whole, all curves that had positive slope no inflection point are following the general law of increased with temperature rise. In addition, compared with pure water system, several kinds of additive solution basically all could effectively reduce the phase equilibrium that was mean reduce the formation pressure. But individual solution improved the phase equilibrium that inhibited the formation of hydrate such as 700 ppm PEG solution. In addition some kinds of solution play a promoting role in a certain temperature range but had inhibitory effect in another temperature range. For example the ionic liquids synthesized by the team had a strong inhibitory effect in high temperature. Every kinds of accelerant have a optimal concentration range. Through compared with curve we found the solution of $700 \mathrm{ppm}$ SDBS, $300 \mathrm{ppm}$ CTAB, 900 ppm PEG, 500 ppm P123, 300 ppm [HMIPS]Ss and 500 ppm [HMIPS]OTs was the best promote concentration respectively. Theirs phase equilibrium curve were showed in Figure 9 separately.

Figure 9 shows that with the reduce of temperature, according to the curve trend could determine the formation of hydrate critical pressure and critical pressure of pure water system is about 1.4 Mpa and when temperature is $2^{\circ} \mathrm{C}$ pressure is below $1.5 \mathrm{Mpa}$. So the promotion of accelerate has limit effect in the low temperature range and the energy to cool increased greatly. In addition, the picture shows that accelerate play a significant role in high temperature section but the formation pressure still very high. It needs great demand for the reliable operation of production and takes lots of time to inducing under the condition of high temperature. The production of $4{ }^{\circ} \mathrm{C}-5^{\circ} \mathrm{C}$ condition is easy to achieve and energy consumption is decreased obviously. Under this condition the additives effect on reducing the pressure is bigger than high temperature section and reduce the burden of the equipment and the hydrate formation rate is accelerated obviously and the feasibility of industrial production greatly improved. As illustrate in Figure 9, 500 ppm [HMIPS]OTs solution is the best accelerate to reduce the hydrate formation pressure under the condition of temperature is between $4{ }^{\circ} \mathrm{C}$ and $5^{\circ} \mathrm{C}$. The formation pressure is $1.88 \mathrm{Mpa}$ when the temperature is $5^{\circ} \mathrm{C}$ which has a $27.1 \%$ lower than that of pure water system.

\subsection{The Influence of Additives on the Induction Time}

Figure 10 shows that under the condition of temperature is $5^{\circ} \mathrm{C}$ and the phase equilibrium is reduced and the optimal concentration solution different kinds of accelerate that chose in this experiment the influence of additives on the induction time.

Through the analysis of Figure 10, as a whole, with the decreasing of initial pressure the induction time rises sharply and regularity is obviously and high pressure in favor of hydrate formation. Compared with the pure water system, SDBS, CTAB and P123 solution has the acceleration on reducing the induction time, the SDBS has the best acceleration. The acceleration of PEG and [HMIPS]Ss solution is not obvious. The [HMIPS]OTs 


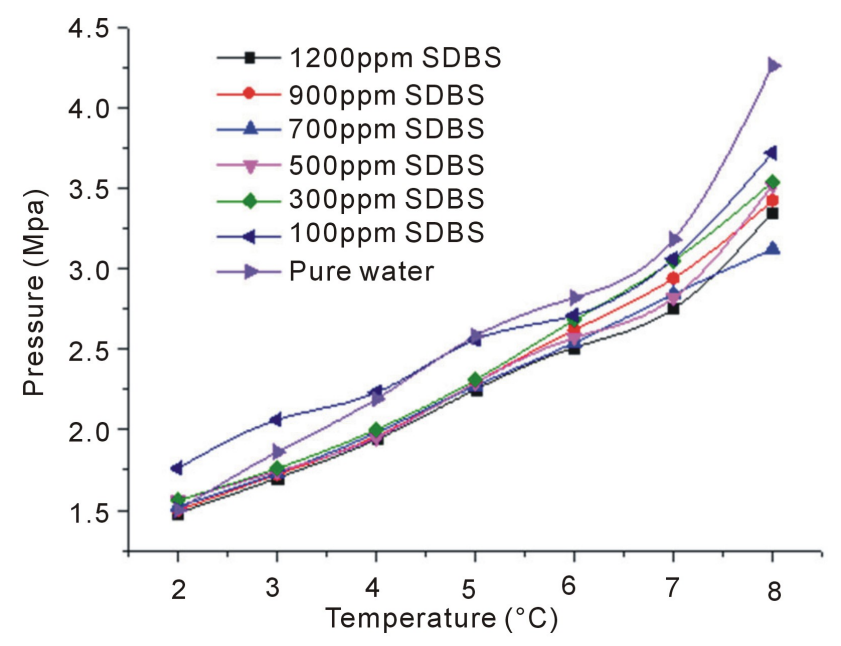

Figure 3. The curve of $\mathrm{CO}_{2}$ hydrate equilibrium in SDBS system.

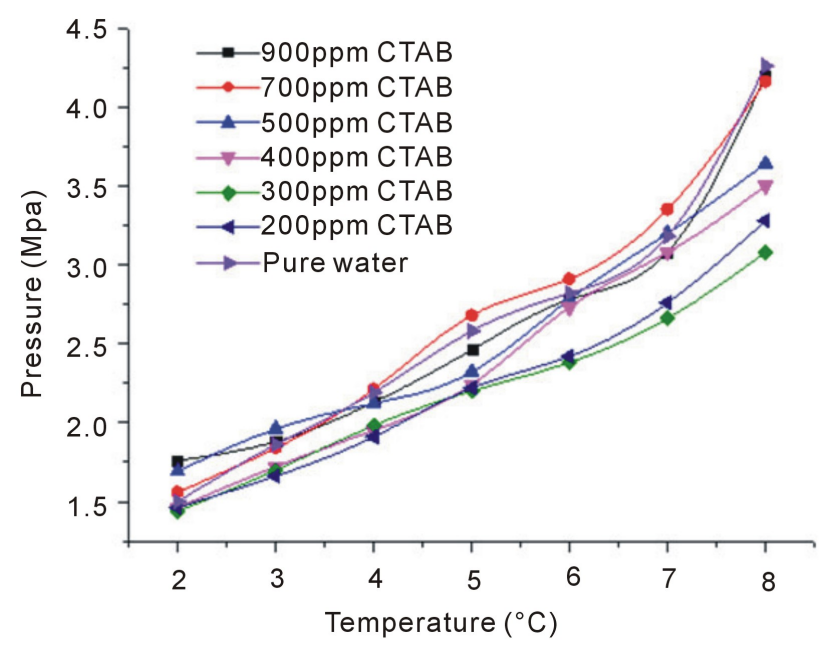

Figure 4. The curve of $\mathrm{CO}_{2}$ hydrate equilibrium in CTAB system.

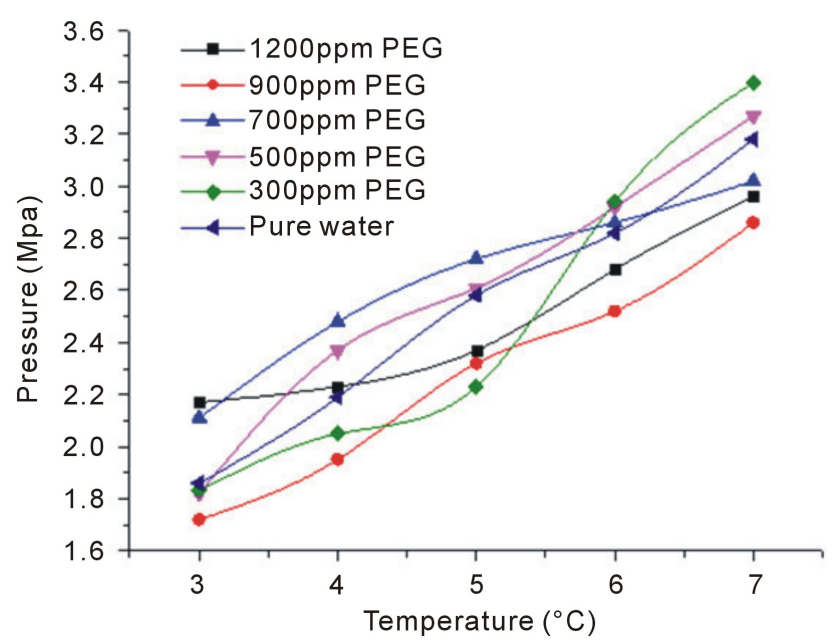

Figure 5. The curve of $\mathrm{CO}_{2}$ hydrate equilibrium in PEG system. 


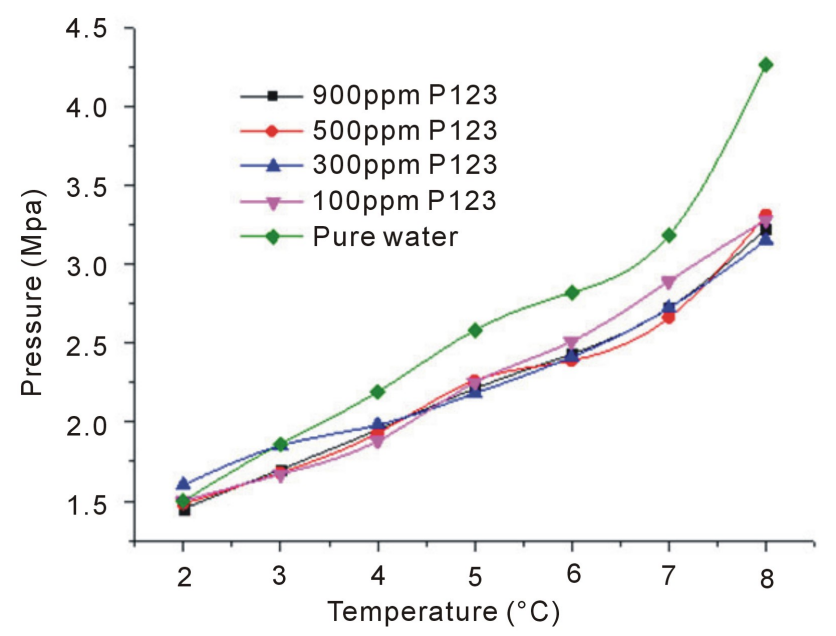

Figure 6. The curve of $\mathrm{CO}_{2}$ hydrate equilibrium in $\mathrm{P} 123$ system.

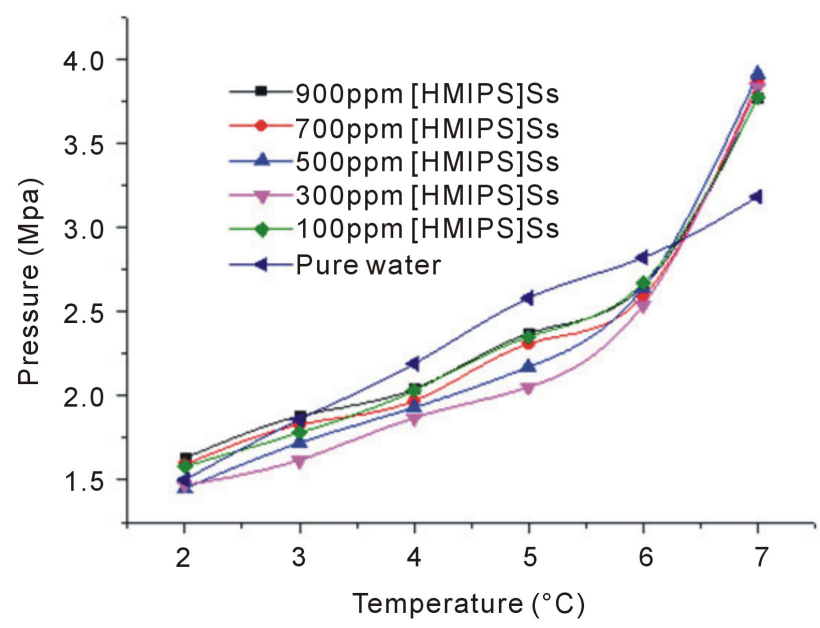

Figure 7. The curve of $\mathrm{CO}_{2}$ hydrate equilibrium in [HMIPS]Ss system.

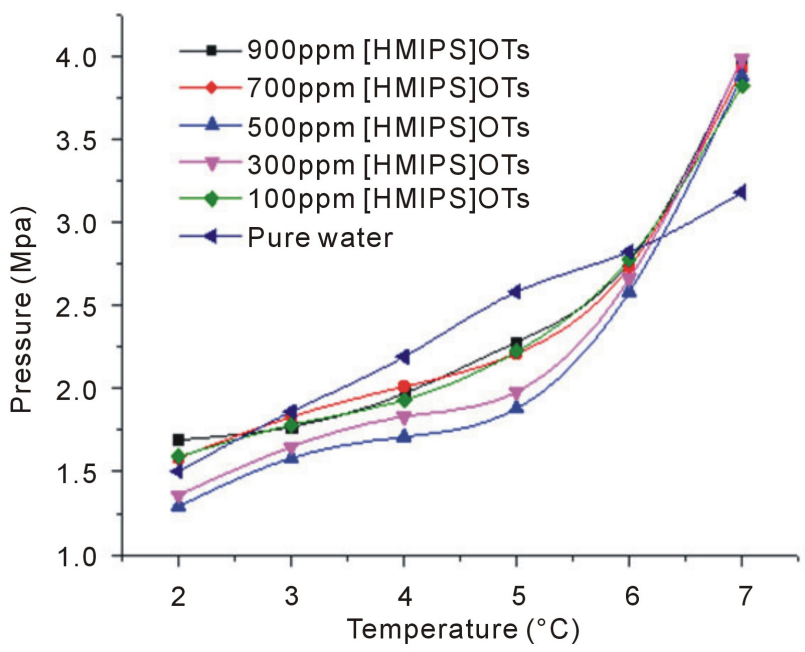

Figure 8. The curve of $\mathrm{CO}_{2}$ hydrate equilibrium in [HMIPS] OTs system. 


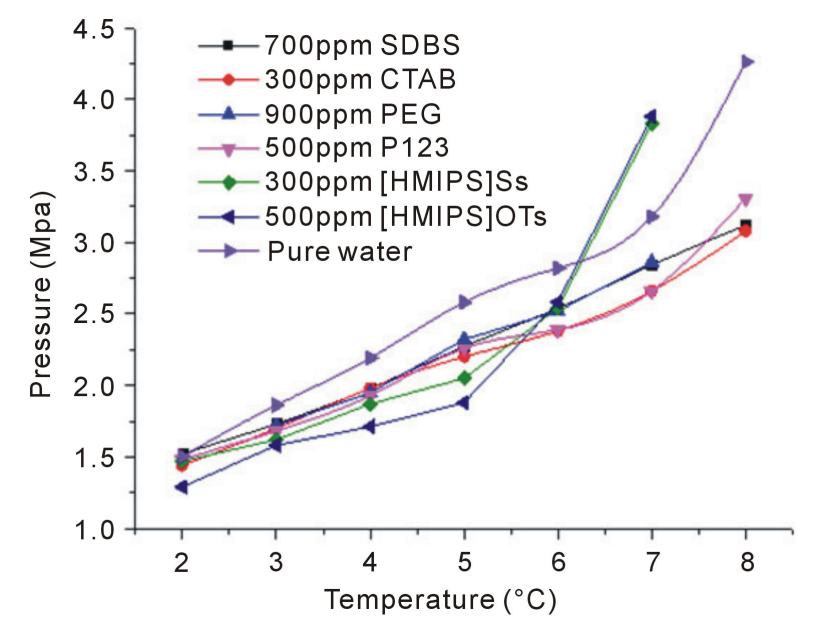

Figure 9. The best promote concentration of $\mathrm{CO}_{2}$ hydrate equilibrium in different acceleration system.

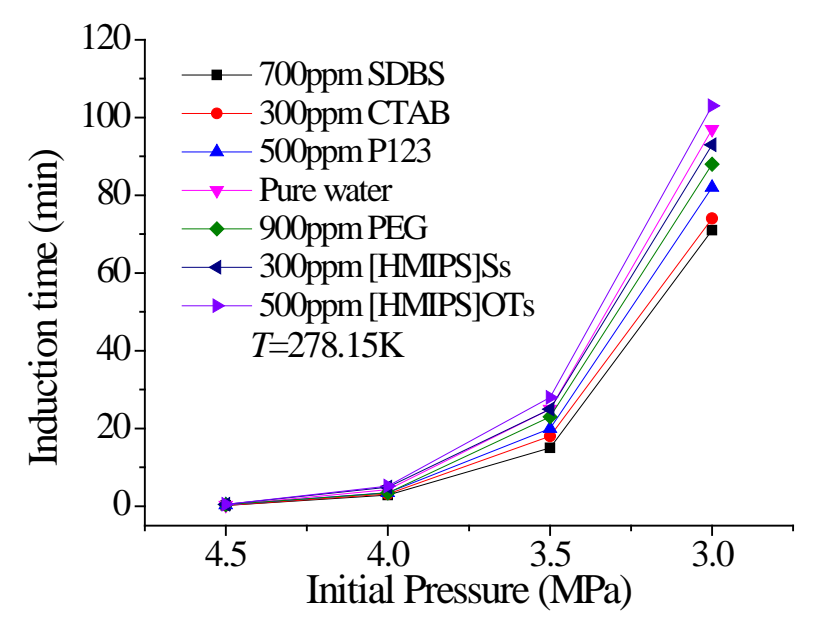

Figure 10. The different acceleration effect on induction time at temperature $5^{\circ} \mathrm{C}$ under the condition of reduction phase equilibrium and the best promote concentration.

which has the best effect on reduce phase equilibrium has the inhibition but the inhibition effect is poor. Specifically, when the initial pressure was $4.5 \mathrm{Mpa}$ the induction time never more than 30s; when the pressure was 4.0 Mpa the time in pure water system was $4 \mathrm{~min} 15 \mathrm{~s}$ and the SDBS was the best its time was 2 min $50 \mathrm{~s}$, [HMIPS]OTs needs the longest time about $5 \min 10 \mathrm{~s}$. When the pressure was $3.5 \mathrm{Mpa}$, the induction time of pure water system was $25 \mathrm{~min}$, SDBS was the best its time was $15 \mathrm{~min}$, [HMIPS]OTs needs the longest time about $28 \mathrm{~min}$. Under the condition of initial pressure was 3.0 Mpa, induction time increased sharply, SDBS need shortest time but still more than $70 \mathrm{~min}$ and the difference between each curve was widened obviously.

Analysis the aim at industrial production oriented, when the initial pressure was under 3.5 Mpa the induction time of hydrate formation was too long which could not meet the industrial production. What's more, under the condition of pressure was 4.0 Mpa the acceleration of hydrate formation rate was limited but energy consumption was increased or mechanical reliability was unreliable under condition of high pressure. Finally, the equilibrium of same phase was compared; the best initial pressure that is overpressure degree $(\Delta \mathrm{P})$ to enhancement hydrate formation rate was $1.5 \mathrm{Mpa}$.

\subsection{Ionic Liquid Effect on Hydrate Formation}

There are five- or six-membered ring of water molecules in water freely. They rely on hydrogen bonding to- 
gether. With the increase of subcooling and supersaturation of gas, the water molecules was increased then gather together. Finally, due to the hydrogen bonding forming the critical size cage-like crystalline and growing for macro crystalline. Gas molecule was wrapped into a cage cavity, a large gathering of crystalline forming the hydrate at last.

1) Through analysis the hydrate nucleation mechanism from the micro angle, it is observed that the number of water molecules in initial water affect the hydrate formation condition and determine the length of induction directly. The number of water molecules determined by the strength of hydrogen bonds directly. So it is beneficial to strengthen the hydrogen bonds to reduce the hydrate formation conditions. Because the ionic get the charge, which will strengthen the polarity of oxygen atoms and thus strengthen then hydrogen bonds which will increase the number of hydrogen bonds. According to the document [5], a certain concentration of $\mathrm{NaCl}$ in reaction system could promote the hydrate formation. The ionic liquids that synthesized by the team was ionic and strengthen the hydrogen bonds, so as to promote the hydrate formation.

2) The seven-membered ring structure of the molecule made by six methylene and lminium ion in HMIPS was too large. In the nucleation process, the gas molecules were inhibited to be wrapped into the cage hole and reduction the hydrate nucleation rate, so as to lengthen the induction time.

\section{Conclusions}

1) In the experiment, stirring had no effect on reducing the hydrate formation pressure, but reduced the induction and response time of hydrate formation obviously. What's more, in the stirring system, hydrate has the transformation process from bubbles to crystalline.

2) In terms of reducing hydrate formation pressure, all additives used in the experiment could reduce the phase equilibrium effectively and improve the hydrate formation conditions. Every acceleration had its best concentration range: 700 ppm SDBS, 300 ppm CTAB, 900 ppm PEG, 500 ppm P123, 300 ppm [HMIPS]Ss, and $500 \mathrm{ppm}$ [HMIPS]OTs is the best concentration of solution. The solution of $500 \mathrm{ppm}$ [HMIPS]OTs had the best effect; when the formation pressure was $1.88 \mathrm{Mpa}$ and temperature was $5^{\circ} \mathrm{C}$, phase equilibrium was $27.1 \%$ lower than that of pure water system. In the terms of reducing the hydrate induction time, surfactant had the best effect, and ionic liquid had the inhibitory effect, but the effect was weak.

3) As a whole, the solution of 500 ppm [HMIPS]OTs was the best single acceleration to strengthen the hydrate formation. We should consider using together with the other additives and developing some more efficient compound additives.

4) Aiming at industrial production, temperature $4^{\circ} \mathrm{C}$ to $5^{\circ} \mathrm{C}$ was the best temperature range to form hydrate and additives had the best effect on reducing phase equilibrium. Compared with the phase equilibrium, the best initial pressure which was overpressure degree to enhance hydrate formation rate was $1.5 \mathrm{Mpa}$.

\section{Acknowledgements}

This work was financially supported by the National Science Foundation of China (No. 51176015).

\section{References}

[1] Gudmundsson, J.S., Khokhar, A.A. and Parlaktuna, M. (1990) Storage of Natural Gas as Frozen Hydrate. Proceedings of 67th Annual Technical Conference and Exhibition of SPE, Washington DC, 4-7 October 1990, 699-707.

[2] Fan, S.S. and Chen, Y. (2001) Natural Gas Hydrate Research Present Situation and the Development Tendency. CAS Bulletin, 2, 106-110.

[3] Klapproth, A., Techmer, K.S., Klapp, S.A., et al. (2007) Microstructures of Gas Hydrates in Porousmedia. International Conferences on the Physics and Chemistry of Ice, Bremerhaven, 24-28 July 2006, 321.

[4] Wang, S.L. and Yu, H.J. (2011) Experiment Study of Compound Additive Effect on $\mathrm{CO}_{2}$ Hydrate Formation and Establish the Dynamics Model. Natural Gas Chemical Industry, 36, 20-22.

[5] Wang, S.L. and Song, Q. (2009) Different Compound Additives Effect on Hydrate Formation under Different System. Natural Gas Chemical Industry, 34, 44-48.

[6] Zhong, Y. and Rogers, R.E. (2000) Surfactant Effects on Gas Hydrate Formation. Chemical Engineering Science, 55, 4175-4187.

[7] Zhang, C.S., et al. (2003) Different Types of Surfactant Effect on Natural Gas Hydrate Formation. Natural Gas Indus- 
try, 23, 91-95.

[8] Wu, Q. and Zhang, B.Y. (2006) The Thermodynamic Function of Surfactant Effect on Gas Hydrate Formation. Journal of Chemical Engineering, 57, 2793-2797. http://dx.doi.org/10.1016/S0009-2509(00)00072-5

[9] Hu, L. (2006) Experiment of Hydrate Formation Dynamics and Model Studying. China University of Petroleum Beijing, Beijing. 